\title{
Model of Risk Assessment of Urban Commercial Complex Investment
}

\author{
Liangli Xiao ${ }^{1, a^{*}}$, Jian wei $\mathrm{Han}^{2, \mathrm{~b}}$ and Mingyang $\operatorname{Pan}^{3, \mathrm{c}}$ \\ ${ }^{1,2,3}$ School of civil Engineering and Architecture, Wuhan University of science and \\ Technology, Wuhan 430070, China. \\ a605316713@qq.com, b284339748@qq.com,'905526634@qq.com \\ ${ }^{1}$ Full address of first author, including country \\ ${ }^{2}$ Full address of second author, including country \\ ${ }^{3}$ List all distinct addresses in the same way \\ aemail, bemail, ${ }^{c}$ email \\ * please mark the corresponding author with an asterisk
}

Keywords: Urban commercial complex ; Investment analysis; Risk assessment

Abstract. Based on the theory of investment risk assessment of Urban Commercial Complex and combined with domestic and foreign scholars research, investment risk of Urban Commercial Complex is predicted and evaluated qualitatively and quantitatively by the use of Analytic Hierarchy Process, Gray Theory, Fuzzy Comprehensive Method, which can provide scientific mathematics theoretical support for urban commercial complex investment.

\section{Introduction}

In recent years, with the development trend of China's urban metropolis, the central area of the city turns single center into multiple centers, and Urban Commercial Complex is an important part of this change. Urban commercial complex has a long investment cycle, large capital investment, poor liquidity, vulnerable policy constraints, so it is difficult to evaluate the investment risks. Concerned about the actual situation of the project, the project is validated and determined by the objective data to make sure that it is feasible or not.

\section{Determination of risk assessment index of urban commercial complex investment}

On the current status of investment risks of urban commercial complex, indicators of decomposition method are taken. Thus the investment risk factors are divided into five categories. According to the risk index system of project investment evaluation, AHP,Gray Theory, Fuzzy Comprehensive Method are supplied to analysis the possible size of the investment risk of Urban Commercial Complex in Wuhan[1,2].

\section{Model of risk assessment urban commercial complex investment}

\section{Decide the weight of index with AHP}

According to hierarchical models of investment risk of Urban Commercial Complex and characteristic of specific risk factors as shown in Table 1, in expert's opinion, analytic hierarchy process is applied in this paper[3]. The main principle: two factors compare with each other in layers, then get the relative importance by taking $1,2, \ldots, 9$, and their reciprocal of the scale, next each weights of the risk are obtained, as shown in Table 1. 
Table 1 Risk assessment index of Urban Commercial Complex investment

\begin{tabular}{|c|c|c|c|c|c|}
\hline Target & Guidelines & Weigh & Index & Weight & Comprehensive weight \\
\hline \multirow{9}{*}{$\begin{array}{c}\text { Risk } \\
\text { Assessment } \\
\text { index } \\
\text { of } \\
\text { Urban }\end{array}$} & \multirow{3}{*}{$\begin{array}{c}\text { Economic Risk } \\
\text { (U1) }\end{array}$} & \multirow{3}{*}{0.27} & Liquidity risk & 0.323 & 0.087 \\
\hline & & & Market supply and demand u2 & 0.476 & 0.128 \\
\hline & & & Economic fluctuations $\mathrm{u} 3$ & 0.201 & 0.054 \\
\hline & \multirow{3}{*}{$\begin{array}{l}\text { Policy Risk } \\
\text { (U2) }\end{array}$} & \multirow{3}{*}{0.12} & Real estate policy & 0.392 & 0.047 \\
\hline & & & District planning & 0.36 & 0.043 \\
\hline & & & Financial support & 0.248 & 0.029 \\
\hline & \multirow{3}{*}{$\begin{array}{c}\text { Technical Risk } \\
\text { (U3) }\end{array}$} & \multirow{3}{*}{0.2} & Quality and safety & 0.247 & 0.049 \\
\hline & & & Cost Control & 0.27 & 0.054 \\
\hline & & & Tenant mix and layout & 0.483 & 0.096 \\
\hline \multirow{6}{*}{$\begin{array}{l}\text { Commercial } \\
\text { Comlex } \\
\text { Investment }\end{array}$} & \multirow{2}{*}{$\begin{array}{c}\text { Decisional Risk } \\
\text { (U4) }\end{array}$} & \multirow{2}{*}{0.11} & Market positioning & 0.646 & 0.071 \\
\hline & & & Development time selection u11 & 0.354 & 0.038 \\
\hline & \multirow{4}{*}{$\begin{array}{l}\text { Manage Risk } \\
\text { (U5) }\end{array}$} & \multirow{4}{*}{0.3} & operational experience $\quad \mathrm{u} 12$ & 0.3 & 0.09 \\
\hline & & & Financial management $\mathrm{u} 13$ & 0.32 & 0.096 \\
\hline & & & Merchants & 0.24 & 0.072 \\
\hline & & & Operate & 0.14 & 0.042 \\
\hline
\end{tabular}

\section{Determination of evaluation matrix and level of assessment}

According to Table 1, risk assessment index of Urban Commercial Complex investment is rated by 10 experts , and the evaluation sample matrix is obtained[4]: $Q=\left(Q_{1}, Q_{2}, Q_{3}, Q_{4}, Q_{5}\right)^{T}$

$Q_{1}=\left[\begin{array}{llllllllll}53 & 49 & 55 & 26 & 88 & 44 & 38 & 29 & 53 & 22 \\ 25 & 66 & 22 & 29 & 75 & 55 & 76 & 35 & 58 & 33 \\ 33 & 63 & 43 & 58 & 52 & 56 & 68 & 52 & 60 & 45\end{array}\right] \quad Q_{2}=\left[\begin{array}{llllllllll}62 & 65 & 51 & 48 & 38 & 40 & 72 & 45 & 69 & 31 \\ 54 & 30 & 45 & 27 & 47 & 22 & 69 & 10 & 58 & 25 \\ 47 & 32 & 46 & 14 & 42 & 25 & 63 & 38 & 43 & 38\end{array}\right]$

$Q_{3}=\left[\begin{array}{llllllllll}72 & 50 & 36 & 35 & 44 & 22 & 45 & 60 & 67 & 24 \\ 46 & 32 & 43 & 32 & 67 & 48 & 57 & 56 & 55 & 21 \\ 67 & 65 & 42 & 40 & 35 & 54 & 93 & 64 & 54 & 32\end{array}\right] \quad Q_{4}=\left[\begin{array}{llllllllll}43 & 54 & 33 & 21 & 42 & 64 & 84 & 42 & 85 & 47 \\ 51 & 47 & 25 & 30 & 54 & 52 & 67 & 53 & 71 & 36\end{array}\right]$

$Q_{5}=\left[\begin{array}{llllllllll}56 & 26 & 56 & 22 & 45 & 32 & 75 & 41 & 79 & 35 \\ 46 & 49 & 48 & 13 & 38 & 30 & 63 & 36 & 48 & 29 \\ 51 & 68 & 47 & 26 & 45 & 34 & 52 & 59 & 63 & 28 \\ 46 & 55 & 34 & 39 & 32 & 55 & 44 & 43 & 66 & 77\end{array}\right]$

\section{Determination of the evaluation gray category}

Extent possible risk factors will be divided to five levels: High Risk (V1), Relative High Risk (V2), Moderate Risk (V3), Relative Low Risk (V4), Low Risk (V5). Thus constituting evaluation criteria set of Urban Commercial Complex investment risk : $V=\left(V_{1}, V_{2}, V_{3}, V_{4}, V_{5}\right)=($ High, Relative High, Moderate, Relative Low, Low), which are represented by digital reviews that assigned to 9,7,5,3,1, and between two can assign 8,6,4,2[4].

Table 2. Gray classification criteria of risk assessment urban commercial complex investment

\begin{tabular}{|c|c|c|c|}
\hline Gray number & Gray grade & Central point & Gray number field \\
\hline 1 & High & 100 & {$[80,120]$} \\
\hline 2 & Relative High & 80 & {$[60,100]$} \\
\hline 3 & Moderate & 60 & {$[40,80]$} \\
\hline 4 & Relative Low & 40 & {$[20,60]$} \\
\hline 5 & Low & 20 & {$[0,40]$} \\
\hline
\end{tabular}

The first category: "high risk" and its whitening weight function denoted ${ }\left(v_{i j}\right)$; second category: "high risk" and its whitening weight function denoted ${ }^{f_{2}\left(v_{i j}\right)}$; third category: "medium risk", the whitening weight function denoted ${ }^{f_{3}\left(v_{i j}\right)}$; Section four categories: "low risk", the whitening weight function denoted ${ }^{f_{4}\left(v_{i j}\right)}$; fifth category: "low risk", the whitening weight function denoted $f_{5}\left(v_{i j}\right)$. 


$$
\begin{aligned}
& f_{1}\left(v_{i j}\right)=\left\{\begin{array}{cll}
0, & v_{i j} \notin[80,120] \\
\frac{v_{i j}-80}{20}, & v_{i j} \in(80,100] \\
\frac{120-v_{i j}}{20} & v_{i j} \in(100,120)
\end{array} f_{2}\left(v_{i j}\right)=\left\{\begin{array}{cc}
0, & v_{i j} \notin[60,100] \\
\frac{v_{i j}-60}{20}, & v_{i j} \in(60,80] \\
\frac{100-v_{i j}}{20} & v_{i j} \in(80,100)
\end{array}\right.\right. \\
& f_{3}\left(v_{i j}\right)=\left\{\begin{array}{cll}
0, & v_{i j} \notin[40,80] \\
\frac{v_{i j}-40}{20}, & v_{i j} \in(40,60] f_{4}\left(v_{i j}\right)=\left\{\begin{array}{cc}
0, & v_{i j} \notin[20,60] \\
\frac{80-v_{i j}}{20} & v_{i j} \in(60,80)
\end{array} \quad v_{i j} \in(20,40]\right. \\
\frac{v_{i j}-20}{20}, v_{i j} & v_{i j} \in(40,60)
\end{array}\right. \\
& f_{5}\left(v_{i j}\right)=\left\{\begin{array}{cc}
0, & v_{i j} \notin[0,40] \\
\frac{v_{i j}}{20}, & v_{i j} \in(0,20] \\
\frac{40-v_{i j}}{20} & v_{i j} \in(20,40)
\end{array}\right.
\end{aligned}
$$

Gray statistical evaluation matrix can be calculated by $n_{i j}=\sum_{j=1}^{n} f_{k}\left(v_{i j}\right)$, where $v_{i j}$ is the evaluation of $\mathrm{i}$ index from $\mathrm{j}$ expert.

\section{Calculation of project risk by Fuzzy}

The weight of Gray evaluation can be calculated by $r_{i j}=n_{i j} / n_{i}$, then get fuzzy evaluation matrix :

$$
B_{1}=\left[\begin{array}{ccccc}
0.04 & 0.06 & 0.27 & 0.405 & 0.225 \\
0 & 0.185 & 0.28 & 0.255 & 0.28 \\
0 & 0.06 & 0.57 & 0.335 & 0.035
\end{array}\right]
$$

Similarly available $B_{2} \sim B_{5}$

\section{Grey Clustering Evaluation of project}

$C_{1}=W_{1} \cdot B_{1}=(0.323,0.476,0.201) \cdot\left[\begin{array}{ccccc}0.04 & 0.06 & 0.27 & 0.405 & 0.225 \\ 0 & 0.185 & 0.28 & 0.255 & 0.28 \\ 0 & 0.06 & 0.57 & 0.335 & 0.035\end{array}\right]$

$=(0.013,0.120,0.335,0.320,0.213)$

Similarly available $C_{2} \sim C_{5}$

\section{Matrix integrated clustering}

$$
\begin{aligned}
& C=W \cdot B=\left(W_{1}, W_{2}, W_{3}, W_{4}, W_{5}\right) \cdot\left(C_{1}, C_{2}, C_{3}, C_{4}, C_{5}\right)^{T} \\
& (0.27,0.12,0.2,0.11,0.3) \cdot\left[\begin{array}{ccccc}
0.013 & 0.12 & 0.335 & 0.32 & 0.213 \\
0 & 0.075 & 0.297 & 0.432 & 0.196 \\
0.031 & 0.091 & 0.358 & 0.388 & 0.132 \\
0.029 & 0.145 & 0.282 & 0.409 & 0.135 \\
0 & 0.085 & 0.284 & 0.463 & 0.168
\end{array}\right]
\end{aligned}
$$

$=(0.014,0.11,0.324,0.350,0.175)$

$$
Z=C \cdot V^{T}=(0.014,0.11,0.324,0.35,0.175)(9,7,5,3,1)^{T}=3.714
$$

Determine the level of risk between the low and medium risk. This shows that the investment risk of the urban commercial complex in general, and in accordance with the actual situation. As can be seen from the results of the decision-making matrix, commercial complex in the city where there is a big 
risk of investing in certain areas, such as Market supply and demand,Tenant mix and layout,Financial management. Therefore, developers should take effective and preventive measures in the above areas to ensure investment security.

\section{Summary}

In our country, project investment risk is studied a lot . Taking into account the specific circumstances of urban commercial complex differences, therefore the investment risk evaluation is not entirely consistent. This evaluation index system of this article, only the combination of the project design. For other urban commercial complex evaluation system can be fine-tuned. This paper carried out the risk evaluation of the degree of urban commercial complex investment qualitatively and quantitatively,and handle both Gray and Fuzzy comprehensive evaluation of the problem. Therefore, the model of risk assessment of Urban Commercial Complex investment can be more objective, scientific and effective assessment of investment risk urban commercial complex, reducing subjective factors, self-examination and self-assessment are much easier for developers, also are to strengthening the management of investment risk targeted to take precautions so important.

\section{References}

[1] Liu si-feng, Xie Nai-ming, New grey evaluation method based on reformative triangular whitenization weight function, J .Systems Engineering. 26(2011) 244-250.

[2] A Marco, Project Feasibility, J .Project Management for Facility Constructions. (2011)124-132.

[3] Gao Lei, Model of Risk Assessment of Urban Commercial Complex Investment, J .Young Science.34(2013) 235-236.

[4] Han Jian-wei, Research and Application of Control Mechanism of Investment Risk of Urban Commercial Complex, Wu Han,2013 